\title{
Evaluation of gamma radiation exposure in a room from construction material
}

\author{
C.S. Sumithrarachchi ${ }^{a}$, A.S.Amerasekera ${ }^{b}$, R.Hewamanna ${ }^{* a}$ and S.R.D.Rosa $^{b}$ \\ ${ }^{a}$ Radioisotope Centre, University of Colombo, Colombo 03, Sri Lanka \\ ${ }^{b}$ Department of Physics, University of Colombo, Colombo 03, Lanka
}

\begin{abstract}
The presence of radioactivity in building materials can be a potential hazard from external exposure to gamma and beta radiation. Indoor radiation comes mainly from the activity concentration of the natural radionuclides of ${ }^{238} \mathrm{U},{ }^{232}$ Th and ${ }^{40} \mathrm{~K}$ in building materials. The calculations presented in this paper indicate if clay bricks containing average activity concentrations of 35,72 and $585 \mathrm{~Bq} \mathrm{~kg}$ of ${ }^{226} \mathrm{Ra},{ }^{232} \mathrm{Th}$ and ${ }^{40} \mathrm{~K}$ respectively are used to construct walls of a room of dimensions $3 \mathrm{~m} \times 3 \mathrm{~m} \times 0.1 \mathrm{~m}$ and $3.6 \mathrm{~m} \times 3 \mathrm{~m} \times 0.1 \mathrm{~m}$ the annual effective gamma radiation dose to a person with an occupancy factor of one is 1.65 $\mathrm{mSv}$. This result can therefore be regarded as an upper limit on the expected exposure. Considering average activity concentrations of 55,56 and $39 \mathrm{~Bq} \mathrm{~kg}^{-1}$ for ${ }^{226} \mathrm{Ra}, 129,50$ and $44 \mathrm{~Bq} \mathrm{~kg}^{-1}$ for ${ }^{232} \mathrm{Th}, 1349,1436$ and $1725 \mathrm{~Bq} \mathrm{~kg}^{-1}$ for ${ }^{40} \mathrm{~K}$ for granite, Lanka and Royal Ceramic floor tiles respectively the annual gamma exposure due to these floor materials is 92, 69 and $61 \mathrm{nSv}$. The results suggest the exposure from the floor materials to be insignificant. The annual effective dose from construction materials is directly proportional to the activity concentration of the radionuclides present in the construction materials.
\end{abstract}

\section{INTRODUCTION}

The presence of radioactivity in building materials can be a potential health hazard both from external exposure to gamma and beta radiation resulting from decay of radionuclides in the building materials and internal exposure due to inhalation of radon progeny resulting from the decay of radon exhaled from the material. The most important source of external radiation exposure in dwellings is caused by the gamma rays emitted from members of the uranium and thorium decay chains and from ${ }^{40} \mathrm{~K}$

\footnotetext{
${ }^{*}$ Corresponding author
} 
occurring naturally in building materials. ${ }^{232} \mathrm{Th}$ and ${ }^{236} \mathrm{U}$ average values of the specific radioactivity concentrations of clay bricks used in Sri Lanka are below the world values for typical masonry while the value for ${ }^{40} \mathrm{~K}$ is higher ${ }^{1}$. During the recent years more and more new floor materials both local and imported are used in office and house constructions. Granite is one such popular flooring due to the ease of maintenance. Granite in particular may contain concentrations of radionuclides of the ${ }^{238} \mathrm{U}$ series. However raw materials and processed building products (particularly floor tiles) can vary in the radionuclide content.

This study presents estimates of the radiation doses that may result from external exposure to gamma radiation resulting from the use of clay bricks for constructing walls and different types of floor tiles more commonly used. Such estimates would enable to assess any possible radiation hazard by the use of such materials and develop necessary standards for the use of building materials.

\section{THEORY}

For a slab of floor tile or brick of dimensions a,b and c placed horizontally at a distance $h$ above a measurement point $\left(x^{\prime}, y^{\prime}, h\right)$ as shown in Fig.1 the gamma radiation dose was calculated in the present study by assuming that the building material giving rise to the dose is infinitely thick. If attenuation in the air and the brick/tile is neglected and if self shielding of body organs is also neglected the annual equivalent dose in Sv received in time $\mathrm{T}(\mathrm{s})$ by a person exposed to gamma radiation at $1 \mathrm{~m}$ height from ground level at the middle point of a room lined with brick walls / floor tiles containing radionuclides, is given by ${ }^{2}$

$$
H_{E}=f\left(\frac{\mu_{a}}{\rho_{a}}\right)_{a v g} E_{t o t} \rho S T \sum_{i} G_{i}
$$

where $f$ is a conversion factor from absorbed dose rate to equivalent dose, $\rho$ is the density of the brick/ floor tile $\left(\mathrm{kg} \mathrm{m}^{-3}\right), \mathrm{S}$ is the activity concentrations $\left.(\mathrm{Bq} \mathrm{kg})^{-1}\right)$ in the brick/floor tile, $\mathrm{E}_{\text {tot }}$ is the total gamma energy per disintegration and $\left(\mu_{\mathrm{a}} / \rho_{\mathrm{a}}\right)_{\text {avg }}$ is the mean energy weighted linear absorption coefficient per unit mass for air. The parameter $\mathrm{G}_{\mathrm{i}}$ depends on the relative geometry of the material containing the radioactivity and the measurement point and has to be calculated numerically. The product $\left(\mu_{\mathrm{a}} / \rho_{\mathrm{a}}\right)_{\mathrm{avg}}$. E $\mathrm{E}_{\mathrm{tot}}$ depends on the energy spectrum of the emitted gamma rays and the absorption properties of the air and $i$ is the $i^{\text {th }}$ wall of the room.

In this study $\left(\mu_{\mathrm{a}} / \rho_{\mathrm{a}}\right)_{\mathrm{avg}}$. $\mathrm{E}_{\text {tot }}$ was calculated using values of $\mathrm{E}, \mathrm{n}(\mathrm{E})$ (the number of gamma photons of energy E per disintegration) and the values of $\left(\mu_{\mathrm{a}} / \rho_{\mathrm{a}}\right)\left(\text { in } \mathrm{cm}^{2} \mathrm{~g}^{-1}\right)^{3}$. 
The product $\left(\mu_{\mathrm{a}} / \rho_{\mathrm{a}}\right)$ avg . $\mathrm{E}_{\text {tot }}$ was calculated for ${ }^{226} \mathrm{Ra},{ }^{232} \mathrm{Th}$ and ${ }^{40} \mathrm{~K}$ separately selecting the most abundant gamma lines. They were $351,609,768,1120,1764 \mathrm{keV}$ for ${ }^{226} \mathrm{Ra}$, $239,338,583,911,968,2614 \mathrm{keV}$ for ${ }^{232} \mathrm{Th}$ and $1460 \mathrm{keV}$ for ${ }^{40} \mathrm{~K}$. The value of $\mathrm{G}$ depends on the orientation of the wall / floor in relation to the measurement point. The G factor for a measurement point with respect to a corner was calculated for the four walls and the floor separately using the standard dimensions of a room ( $3.6 \mathrm{~m} \times 3.0 \mathrm{~m} \times 3.0 \mathrm{~m})$ constructed using single brick lining with an average width of $0.1 \mathrm{~m}$, and three different types of floor tiles with an average width of $0.009 \mathrm{~m}$. The conversion factor $f$ was taken to be $1.105 \mathrm{~Sv} \mathrm{~s}^{-1}\left(\mathrm{~J} \mathrm{~kg}^{-1} \mathrm{~s}^{-1}\right)^{4}$. This is probably an over estimate as it makes no specific allowance for self-shielding of body organs.

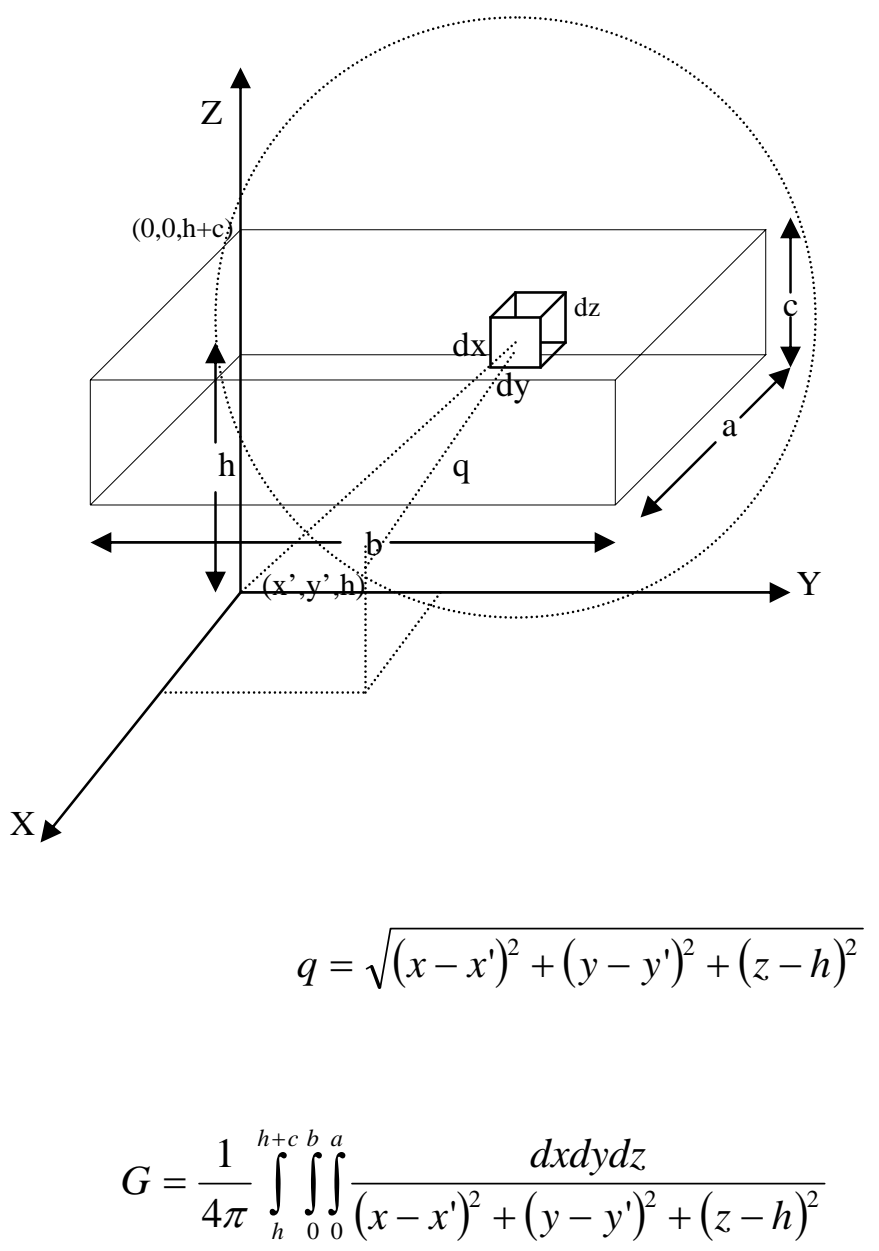

Fig. 1 The geometry of a slab of the construction material 


\section{RESULTS}

The measured average density of bricks was $1200 \mathrm{~kg} \mathrm{~m}^{-3}$. The average dimensions of bricks were $20 \mathrm{~cm} \times 10 \mathrm{~cm} \times 5 \mathrm{~cm}$. The average activity concentrations for clay bricks used in Sri Lanka were taken as 35, 72 and $585 \mathrm{~Bq} \mathrm{~kg}^{-1}$ for ${ }^{226} \mathrm{Ra},{ }^{232} \mathrm{Th}$ and ${ }^{40} \mathrm{~K}$ respectively ${ }^{1}$. The calculated $\left(\mu_{\mathrm{a}} / \rho_{\mathrm{a}}\right)$ avg. $\mathrm{E}_{\text {tot }}$ values for ${ }^{226} \mathrm{Ra},{ }^{232} \mathrm{Th}$ and ${ }^{40} \mathrm{~K}$ were $8.848 \times 10^{-16}, 1.5431 \times 10^{-15}$ and $1.2092 \times 10^{-16} \mathrm{~J} \mathrm{~Bq}^{-1} \mathrm{~s}^{-1} \mathrm{~m}^{2} \mathrm{~kg}^{-1}$ respectively. The exposure time was assumed to be one full year ( $\left.3.1577 \times 10^{7} \mathrm{~s}\right)$. With these values, the equivalent dose due to an infinitely thick clay brick wall for ${ }^{226} \mathrm{Ra}$ is given by

$$
\begin{aligned}
H_{E} & =1.105 \times 1200 \times 35 \times 8.848 \times 10^{-16} \times 3.1577 \times 10^{7} \mathrm{G} \mathrm{Sv}^{-1} \\
& =1.30 \times 10^{-3} \mathrm{G} \quad \mathrm{Sv} \mathrm{y}^{-1}
\end{aligned}
$$

Calculations were done in a similar manner and the values obtained for ${ }^{232} \mathrm{Th}$ and ${ }^{40} \mathrm{~K}$ were $4.65 \times 10^{-3} \mathrm{G}$ and $3.16 \times 10^{-3} \mathrm{G}$ Sv $\mathrm{y}^{-1}$ considering the average activity concentrations respectively. Thus the equivalent dose from the above mentioned radionuclides present in clay bricks amounts to $9.11 \times 10^{-3} \mathrm{G} \mathrm{Sv} \mathrm{y}^{-1}$.

Where there are more than one wall the total equivalent dose can be given by

$$
H \quad=\Sigma_{i} H_{i}=9.11 \times 10^{-3} \Sigma_{i} G_{i} \quad \mathrm{~Sv} \mathrm{y}^{-1}
$$

Calculations were made using the values of $\rho$ and $\mathrm{S}$ as given above and for a single brick wall of thickness $0.1 \mathrm{~m}$. The dose at distances of $1 \mathrm{~m}$ above ground at the center of the room would depend on the dimensions of the wall and the distance of the measurement point from the wall. This is seen from the $G$ values obtained. Calculation of the $G$ factor for a single wall is given in Fig.2. A series of calculations was carried out in a similar manner for the remaining walls and the floor. The $G_{i}$ values obtained for $3 \mathrm{~m}$ x $3 \mathrm{~m}$ x $0.1 \mathrm{~m}$ and $3.6 \times 3 \mathrm{~m}$ x $0.1 \mathrm{~m}$ walls were $6.87 \times 10^{-2}$ and $2.70 \times 10^{-2}$ respectively as given below resulting in a $\Sigma G_{i}$ of $1.91 \times 10^{-1}\left(2 \times 6.87 \times 10^{-2}+2 \times 2.70 \times 10^{-2}\right)$ for walls. 


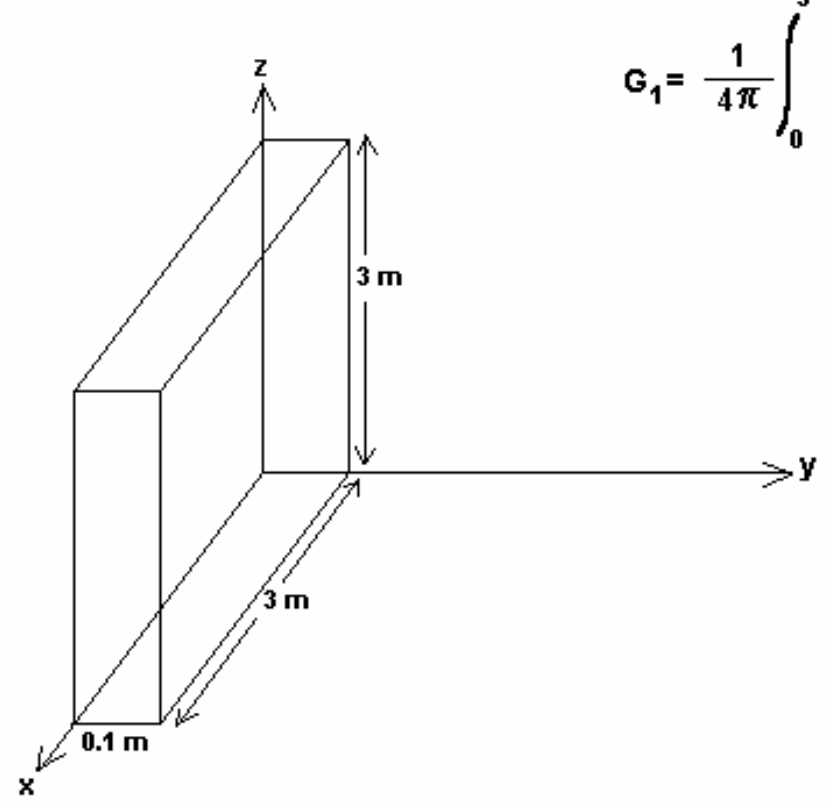

$$
G_{1}=\frac{1}{4 \pi} \int_{0}^{3} \int_{0}^{0.1} \int_{0}^{3} \frac{d x \cdot d y \cdot d z}{(x-1.5)^{2}+(y-1.8)^{2}+(z-1)^{2}}
$$

Fig.2 The geometry of a wall and the $\mathrm{G}_{1}$ calculation

$$
\begin{aligned}
& G_{2}=\frac{1}{4 \pi} \int_{0}^{3} \int_{3.6}^{3.7} \int_{0}^{3} \frac{d x d y d z}{(x-1.5)^{2}+(y-1.8)^{2}+(z-1)^{2}} \\
& G_{3}=\frac{1}{4 \pi} \int_{0}^{0.1} \int_{0}^{3.6} \int_{0}^{3} \frac{d x d y d z}{(x-1.5)^{2}+(y-1.8)^{2}+(z-1)^{2}} \\
& G_{4}=\frac{1}{4 \pi} \int_{3}^{3.1} \int_{0}^{3.6} \int_{0}^{3} \frac{d x d y d z}{(x-1.5)^{2}+(y-1.8)^{2}+(z-1)^{2}}
\end{aligned}
$$

Thereby for a room of size $3 \mathrm{~m} \times 3.6 \mathrm{~m} \times 3 \mathrm{~m}$ the estimated equivalent dose at a height of $1 \mathrm{~m}$ from the center of the floor $-H_{E}$ for the average activity concentrations for

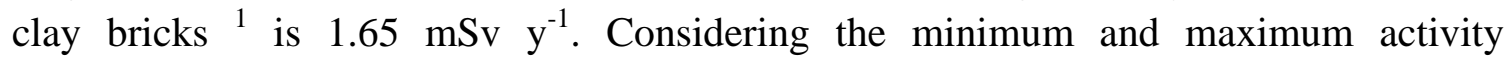


concentration ${ }^{1}$ the estimated equivalent doses from clay bricks used for construction of walls range from $0.30-3.46 \mathrm{mSv} \mathrm{y}^{-1}$.

Similarly the dose from the floor tiles were calculated. Three different floor tiles were used in this study, granite, Lanka floor tiles and Royal Ceramic. The measured average densities for the three varieties were 2588, 2328 and $2156 \mathrm{~kg} \mathrm{~m}^{-3}$ respectively. A density correction was not carried out as the gamma lines used to calculate the activity concentrations were 1764, 2614 and $1460 \mathrm{keV}$ for ${ }^{226} \mathrm{Ra}$, ${ }^{232} \mathrm{Th}$ and ${ }^{40} \mathrm{~K}$ respectively. The average dimensions of the floor tiles were $10 \mathrm{~cm} \times 10 \mathrm{~cm} \times 0.9 \mathrm{~cm}$. The average activity concentrations were 55, 56 and $39 \mathrm{~Bq} \mathrm{~kg}^{-1}$ for ${ }^{226} \mathrm{Ra}, 129,50$ and $44 \mathrm{~Bq} \mathrm{~kg}^{-1}$ for ${ }^{232} \mathrm{Th}, 1349,1436$ and $1725 \mathrm{~Bq} \mathrm{~kg}^{-1}$ for ${ }^{40} \mathrm{~K}$ for granite, Lanka and Royal Ceramic floor tiles respectively ${ }^{5}$. The calculated $\left(\mu_{\mathrm{a}} / \rho_{\mathrm{a}}\right)_{\text {avg }}$. $\mathrm{E}_{\text {tot }}$ values for ${ }^{226} \mathrm{Ra},{ }^{232} \mathrm{Th}$ and ${ }^{40} \mathrm{~K}$ were $9.1177 \times 10^{-16}, 1.4063 \times 10^{-15}$ and $1.2559 \times 10^{-16} \mathrm{~J} \mathrm{~Bq}^{-1} \mathrm{~s}^{-1} \mathrm{~m}^{2} \mathrm{~kg}^{-1}$ respectively. The $\mathrm{G}$ factor for a room with the floor dimension $3.6 \mathrm{~m} \mathrm{x} 3 \mathrm{~m} \times 1.009 \mathrm{~m}$ was calculated to be $2.64 \times 10^{-6}$ as given below.

$$
G=\frac{1}{4 \pi} \int_{0}^{3} \int_{0}^{3.6} \int_{0}^{0.009} \frac{d x d y d z}{(x-1.5)^{2}+(y-1.8)^{2}+(z-1)^{2}}
$$

The equivalent dose due to the different floor tiles for ${ }^{226} \mathrm{Ra}$ ranged from $2.68 \mathrm{x}$ $10^{-3}-4.53 \times 10^{-3} \mathrm{G} \mathrm{Sv} \mathrm{y}^{-1}$. Similarly $H_{E}$ values for ${ }^{232}$ Th ranged from $4.66 \times 10^{-3}-1.64 \mathrm{x}$ $10^{-2} \mathrm{G} \mathrm{Sv} \mathrm{y}{ }^{-1} . H_{E}$ values for ${ }^{40} \mathrm{~K}$ ranged from $1.47 \times 10^{-2}-1.63 \times 10^{-2} \mathrm{G} \mathrm{Sv} \mathrm{y}^{-1}$. The estimated annual doses from floor tiles used for construction are 92, 69 and $61 \mathrm{nSv}$ for granite, Lanka tiles and Royal Ceramic floor tiles respectively. The total dose due to construction materials - clay bricks and floors tiles (granite, Lanka tiles and Royal Ceramic) for a standard size room would not be significantly greater than $1.65 \mathrm{mSv} \mathrm{y}^{-1}$.

\section{DISCUSSION}

Surveys of the dose rate in air from terrestrial gamma rays inside dwellings representing over a third of the world population range from $0.07-14.7 \mathrm{mSv} \mathrm{y}^{-1}{ }^{6}$. The results reported here can be considered as upper limits of the annual doses because the calculations were made on the following assumptions. The exposed individual spends one full year at the point of exposure, there is no attenuation in the air or the wall, and these are blank walls, there is no self shielding of the body organs and that all radionuclides whose gamma lines were considered present in the clay bricks contribute to the gamma radiation thereby giving rise to exposure. The dose from the floor materials 
is insignificant. It has to be borne in mind that there will be a reduction in the doses estimated due to the presence of doors and windows, as they do not contribute to the gamma dose.

\section{REFERENCES}

1. R.Hewamanna, C.S.Sumithrarachchi, P. Mahawatte, H.L.C.Nanayakkara and H.C.Ratnayake, Natural radioactivity and gamma dose from Sri Lankan clay bricks used in building construction, In Press

2. R.S. O’Brian, Gamma Doses From Phospho-Gypsum Plaster Board, Health Physics 72, 92-96 (1997)

3. The Health Physics and Radiological Health Handbook, edited by B.Shleien (Silver Spring, MD 1992),

p. 147.

4. A. Martin and S. A. Harbison, An Introduction to Radiation Protection (London: Chapman and Hall, 1979), second edition.

5. A.S.Amarasekera Radioactive analysis of common flooring materials used in Sri Lankan environment. B.Sc. Special Degree dissertation 1999

6. UNSCEAR , 1993. United Nations Scientific Committee on the Effects of Atomic Radiation, Exposure from Natural Sources of Radiation. 1993 Report to the General Assembly. 